\title{
Construction survey objects agro industrial complex with system approach
}

\author{
Garkina Irina $^{1,}$, , Garkin Igor ${ }^{1, b}$, Klyuev Sergey ${ }^{2, c}$ \\ ${ }^{1}$ Penza State University of Architecture and Construction \\ Street Titov 28, Penza, Russia, 440028 \\ ${ }^{2}$ Belgorod State Technological University named after V.G. Shukhov \\ Street Kostyukova 46, Belgorod, Russia, 308012 \\ aigor_garkin@mail.ru, bstroyconst@pguas.ru, czhurnalnauka2015@yandex.ru
}

Keywords: Constructions, Buildings, Agro industrial complex, System approach, Technical survey, Audit of industrial safety

\begin{abstract}
Experience is a survey of building designs of buildings and constructions of agro industrial complex. For effective diagnosis of their condition offered system approach, in which each element is not described as such, and in view of its place in the whole. An example of technical expertise workshop on the production of flour (s. Syuzyum, Kuznetsk area of the Penza region). The resulted method of conducting technical examination of constructions workshop building for the production of flour, can be transferred and used for the inspection of other buildings and structures in the field of agriculture and other industries.
\end{abstract}

\section{Introduction}

Agriculture provides the society vital products and on compliance with the safety standards of buildings and structures depends on food security. Buildings and facilities of agricultural sector: silos, warehouses (storage of fertilizers, agricultural products, etc.), tower silos, loading and unloading stations, etc. - Engineering objects, processes which present a variety of technical devices (bucket elevators, dryers, roller machines, crushers and others.). Complex manufacturing processes; high degree of aggressiveness of the medium (chemicals, fertilizers, humidity, and other parasites.); explosiveness (nitrogen fertilizers, dust, etc.) make the operation of the structures of buildings agricultural sector one of the most important tasks. The objects on which the storage or processing of vegetable raw materials (in the process form explosive dust-air mixture to spontaneous combustion, ignited by an ignition source, or burn yourself), belong to the category of hazardous production facilities.

A number of accidents at the enterprises of agro-industrial complex, including:

- The collapse of the silo idle breeding complex (s.Rogintsy Romny district of Sumy region, Ukraine, 2005);

- The collapse of the elevator (Guizhou Province, China; (2009);

- The collapse of the silo (Fig. 1), a height of 42 meters bread Bendery (Moldova, 2012);

- The collapse of the wall of the elevator Trinity bakery (2012.);

- The explosion in stock fertilizers (g.Vest, Texas, USA, 2013);

- The collapse of the elevator (Fig. 2) Ekaterinburg flour mill (2014).

The main reasons leading to emergency situations on the agricultural sector facilities include:

- Corrosion of the individual structural elements (chemically aggressive environments);

- Structural damage by parasites (insects);

- Destruction of the protective layer construction (concrete, paint, etc.);

- Destruction of the individual structural elements (dynamic load of the operation of crushers, roller machine tools, elevators, etc.);

- Destruction (or weakening) fixing structural elements (dynamic loads, vibration [3]);

- The lack of easy-glider designs in the right amount; 
- The lack of special equipment providing industrial safety (gas analyzers, dust detectors, etc.).

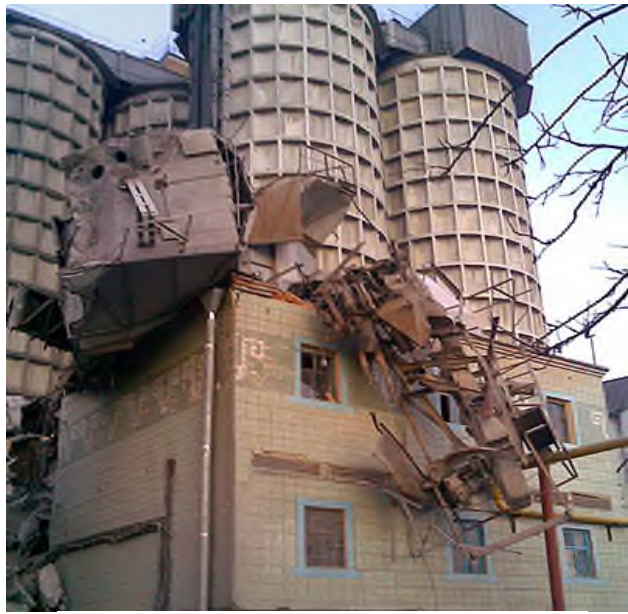

Fig. 1 Collapse of 42-meter silo tower "Bendery bread products".

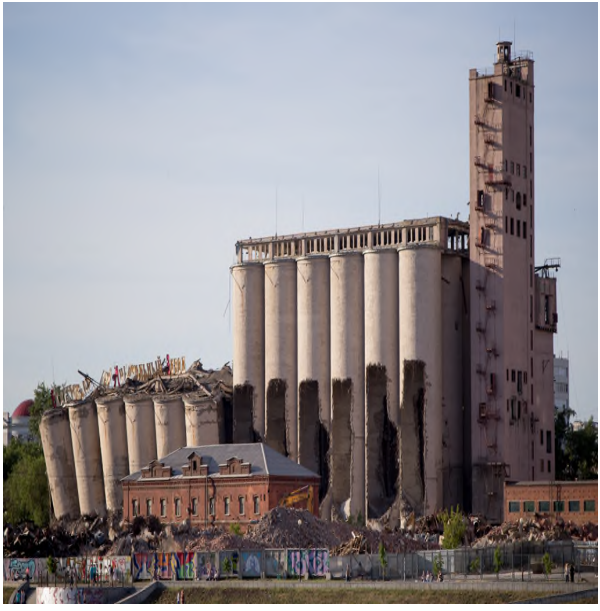

Fig. 2 Collapse of elevator Ekaterinburg flour mill.

Predict which of the main reasons is practically impossible, since a change in any element of the building structure has an impact on other elements of it. Repeatability of accidents with similar causes points to the need to examine factors leading to the critical state of buildings and structures; the need for their analysis, systematization and the efficiency of existing safety management system. Surface analysis of the causes of accomplished tragedies often leads to replication errors in the design, construction and operation [2,3].

Survey of technical condition of buildings and structures is carried out to determine the possibility of further safe operation and identification of the need for rehabilitation work (or overhaul) in three stages:

- Preparations for the survey (carried out with the purpose of acquaintance with the object of the survey, its space-planning and designs, the collection and analysis of technical documentation, preparation of work programs, taking into account the terms of reference agreed with the customer);

- Preliminary (visual) inspection (carried out for the purpose of a preliminary assessment of the technical state of constructions, detected defects and damage by external signs with the necessary measurements and catch);

- Detailed (instrumental) examination (for the most accurate determination of the state structures and their elements are held instrumental and laboratory tests as well as calibration calculations).

Here is an example of the building a survey department for the production of flour (s.Syuzyum, Kuznetsk area of the Penza region), held in 2014 (in the framework of the examination of industrial safety of buildings and structures), experts and non-destructive testing in "Storage and processing of vegetable raw materials."

\section{Method}

Building general built area $6578 \mathrm{~m}^{2}$ was built in 1979, the building envelope are panels of cellular concrete (for heated industrial buildings, column spacing of $6 \mathrm{~m}$, panel thickness $-240 \mathrm{~mm}$ Brand cellular M35 panels of concrete at mark on frost resistance SSE 25; surround weight - 700$800 \mathrm{~kg} / \mathrm{m}^{3}$ ) and ceramic brick M-75; the internal walls are made of ceramic bricks M-75 cementsand mortar grade M-25. During the analysis of the technical documentation and visual inspection the following defects have been identified:

- Lack of the design and operational documentation;

- Cracks in the walls with an opening width of less than $5 \mathrm{~mm}$;

- Exposure of the working reinforcement columns (Fig. 3);

- Weathering joints cover plates (Fig. 4);

- Destruction of the blind area; 
- Detachment of the plaster layer.

Based on an integrated approach within the framework of the technical examination carried out a survey and technical devices in the facility (elevator I-10/5 (15 pcs.), Automatic machines Roller brand ZM (5 pcs.)). Measuring the concentration of explosive dust in the room department revealed no excess concentration.

Physical deterioration of the building is defined by (data in Table 1)

$\Phi_{C}=\sum_{i=1}^{n} \Phi_{k i} \cdot l_{i}$

$\Phi_{c}$ - physical deterioration of the building, \%;

$\Phi_{k i}$ - physical deterioration of a separate structure, component or system, \% ;

$l_{i}$ - coefficient corresponding to the share of the replacement cost of a separate design element or system for a total replacement value of the building;

$n$ - number of individual structures, components and systems in the building.

Table 1. Physical deterioration of the building.

\begin{tabular}{|c|c|c|c|c|c|}
\hline \multirow{2}{*}{$\begin{array}{c}\text { Name of element } \\
\text { structures }\end{array}$} & $\begin{array}{c}\text { The } \\
\text { proportion of } \\
\text { the structural } \\
\text { element,\% }\end{array}$ & $\begin{array}{c}\text { The proportion of } \\
\text { the structural } \\
\text { element by Annex } \\
\text { VSN 53-86 (p), } \%\end{array}$ & $\begin{array}{c}\text { Estimated } \\
\text { specific } \\
\text { element } \\
\text { weight, \% }\end{array}$ & $\begin{array}{c}\text { Physical deterioration of } \\
\text { building elements, \% }\end{array}$ \\
\cline { 4 - 6 } & $\begin{array}{c}\text { According to the } \\
\text { results the full- } \\
\text { scale a survey }\end{array}$ & $\begin{array}{c}\text { Weighted } \\
\text { mean }\end{array}$ \\
\hline Foundations & 4 & 9 & 20 & 15 & 3 \\
\hline Floor & 11 & 10 & 5 & 15 & 0,45 \\
\hline Blind area & 3 & 20 & 5 & 25 & 1,25 \\
\hline Walling & 43 & 86 & 25 & 25 & 6,25 \\
\hline Columns & 5 & 73 & 25 & 20 & 5 \\
\hline Truss construction & 16 & 45 & 20 & 20 & 4 \\
\hline Roof & 7 & 25 & 10 & 20 & 2 \\
\hline \multicolumn{7}{|r|}{ Total physical deterioration of the building: } \\
\hline
\end{tabular}

Despite the fact that the overall wear and tear does not exceed $25 \%$ (classification corresponds to the "usable" category), individual defects (for example, exposure of the working reinforcement, Fig. 3 , a crack, Fig. 4) can cause accidents up to the collapse, as the individual structures, and the whole building.

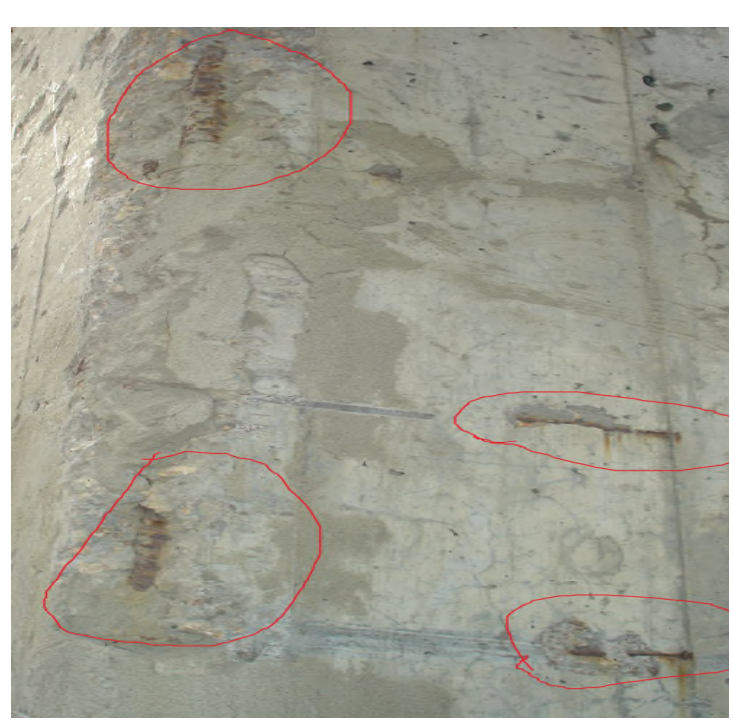

Fig. 3 Bare working armature building columns.

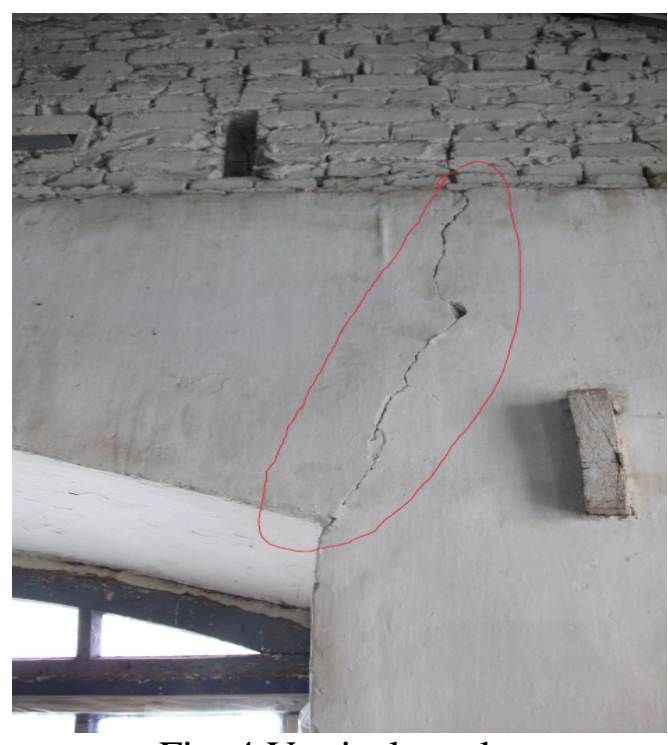

Fig. 4 Vertical crack

(opening width greater than $5 \mathrm{~mm}$ ). 


\section{Results}

Therefore, the results of a survey the following recommendations to eliminate the detected defects have been given:

- Overhaul of the external walls and cover plates;

- Injected into the cracks;

- Restore the protective layer of concrete to enable the work of reinforcing bars;

- Restore the blind area of the building;

- Restore the missing design and operational documentation.

\section{Conclusion}

Problem prevention of emergency situations and the validity of the choice of the complex engineering activities to prevent them always current. A negative factors leading to accidents at facilities of capital construction (including, and the agricultural sector), should identify not after but before the accident, as part of the examination of the safety of buildings and structures. And for a more productive analysis of the state of buildings and structures appropriate to apply a system approach to their study $[2,4,5]$ which is complex: a record of all the relationships, the study of individual structural parts, identifying the role of each of them in the overall functioning of the system and vice versa, identifying the impact of the whole system at some of its elements. Building object is considered as a complex system with all the necessary features (presence of subsystems (elements), connection pooling, perform the operation conditions of integrity). Therefore, the examination should aim to identify and evaluate the interaction of all of its parts and to combine them. In complex systems, which include building frames, parts (sub) systems are so strongly interrelated plurality of forward and backward linkages, that a change in one of them often leads to significant changes in other parts. Here and there is a need to assess and analyze the status of a building structure with a systematic approach, in which each element must not be described as such, and in view of its place in the whole.

\section{References}

[1] A. M. Danilov, I. A. Garkina, I. N. Garkin, Protection from shock and vibration accompanying: exponentially trigonometric function approximation, Reg. Architect. Eng. 3 (2012) 85-88.

[2] I. N. Garkin, I. A. Garkina, Analysis of the causes of collapse of building structures of industrial buildings with a system approach, Almanac Mod. Sci. Edu. 84(5-6) (2014) 48-51.

[3] I. N. Garkin, N. V. Agafonkina, Analysis of the causes of the collapse of cellular tower in the Penza region // Education and science in the modern world, Innov. 3 (2016) 49-56.

[4] I. N. Garkin, I. A. Garkina, System Research at the technical examination of constructions of buildings and structures, Mod. Prob. Sci. Educ. 3 (2014). URL: http://www.scienceeducation.ru/ru/article/view?id=13139.

[5] I. N. Garkin, I. A. Garkina, Systems approach to technical expertise construction of buildings and facilities, Contemp. Eng. Sci. 8(5) (2015). 213-217 http://dx.doi.org/10.12988/ces.2015.5114 